\title{
Editorial
}

\section{Chasqui una alternativa de comunicación en Latonoamérica}

\author{
Gissela DÁVILA COBO \\ Directora General CIESPAL \\ gdavila@ciespal.org
}

Para el Centro Internacional de Estudios Superiores de Comunicación para América Latina (CIESPAL), este número 146 de la Revista Latinoamericana de Comunicación Chasqui, dedicado a "Medios de comunicación alternativos y principios educativos para un nuevo mundo", cobra particular importancia en al menos dos sentidos. El primero tiene que ver con la temporalidad, ya que se trata del primer monográfico del año en el que nos preparamos para celebrar los cincuenta años de la revista.

La trayectoria de una publicación científica, latinoamericana y caribeña, que se ha encargado de recoger las principales discusiones en el mundo de las ciencias sociales, con especial atención en la reflexión sobre la comunicación, hace de Chasqui una fuente muy importante al investigar y estudiar el pensamiento crítico latinoamericano. Sus corrientes ideológicas y las distintas apuestas que se dan desde contextos propios, analizando las realidades sociales que marcan la política, la economía y lo social de una ciudadanía que se abre caminos diversos y con apuestas distintas a las que pueden venir de otros continentes, le otorga un valor -investigativo e histórico - incomparable.

Chasqui tiene identidad propia, aquella que ha consolidado en estos cuarenta y nueve años; promueve un espacio de intercambio, diálogo, apuestas y propuestas por una América distinta, en la que se valora la investigación local con trascendencias nacionales, regionales, continentales y mundiales, siempre anclada al territorio. Este principio dispensa sentido a lo que somos y a lo que pretendemos ser como latinoamericanos.

La comunicación - hemos asumido - es el motor que impulsa los saberes, los idiomas, las costumbres y cosmovisiones de estas Américas, ricas en culturas y ávidas de ser socializadas en espacios sinérgicos en los que no existe la imposición sino la construcción colectiva y equilibrada. Una comunicación que se asienta en las enseñanzas del maestro Paulo Freire y que alcanza dimensiones de organización que han permitido rescatar idiomas, culturas, reivindicar derechos y mantener luchas sociales con objetivos comunes. 
A partir de esta noción se plantea el segundo sentido de importancia en este monográfico, y es que nos permite hacer un recorrido por experiencias de comunicación popular, comunitaria, ciudadana o alternativa que han echado raíces en un campo fértil como nuestro continente.

$\mathrm{Al}$ pensar en esta otra comunicación, necesariamente me refiero a experiencias que han sido posibles mediante la participación organizada de la sociedad, permitiendo la construcción de una "identidad colectiva" (Peppino, 1998) y el reconocimiento del valor en cuanto a la construcción del "común" como factor determinante de una comunicación de la ciudadanía y no manipulativamente para ella (Cerbino, 2018). Dichas experiencias cobran valor y muestran cuán necesario es dejar de concebir la comunicación como escenario de mera transmisión de información para convertirse en vehículo para alcanzar reivindicaciones sociales y defender los derechos de quienes históricamente han sido excluidos.

Esta comunicación "otra" — que se denomina de varias formas - es la que nos da una opción real frente a la comunicación tradicional que solo busca su propio beneficio. Esta alternativa es la que marca la diferencia y construye procesos sociales capaces de cambiar las condiciones de vida de las comunidades desde la organización y la palabra puesta al servicio común.

Chasqui, al ser una revista latinoamericana de comunicación, busca consolidar espacios en donde proyectos sociales, estudios de investigación y propuestas de acción colectiva sean puestos al servicio de la comunidad con rigurosidad académica y pertinencia. Es por ello que este monográfico contribuye a la discusión científica de procesos sociales marcados por medios de comunicación populares, comunitarios y alternativos, dándoles el valor que les corresponde en la construcción de nuestras sociedades.

La selección de los artículos que componen esta publicación se realizó de forma cuidadosa y profesional, gracias al aporte de Juan Fernando Muñoz Uribe - Profesor titular de la Facultad de Comunicación Social-Periodismo de la Universidad Pontificia Bolivariana (Colombia) - y de Paula Renés Arellano - Profesora de Teoría e Historia de la Educación de la Facultad de Educación de la Universidad de Cantabria (España) - , editores temáticos de este número, a quienes agradezco por su rigurosidad y compromiso con este monográfico que sin duda alguna será material de investigación obligatorio al hablar de comunicación latinoamericana. 